Case Study

\title{
A CASE PRESENTATION ON OFLOXACIN INDUCED DERMAL HYPERSENSITIVITY REACTION
}

\author{
BHAVANAM DIVYA ${ }^{1}$ (D), LEDO THANKACHAN ${ }^{*}$ \\ 1Department of Pharmacy Practice, Bhaskar Pharmacy College, Jawaharlal Nehru Technical University, Hyderabad, Telangana, India \\ 500075 \\ *Email: ledo.thankachan@gmail.com
}

Received: 17 Nov 2021, Revised and Accepted: 17 Jan 2022

\begin{abstract}
Ofloxacin is a second-generation fluoroquinolone and is highly effective against a wide range of bacterial infections. Fluoroquinolones are welltolerated drugs with mild-to-moderate adverse effects such as gastrointestinal disturbances, skin reactions, and neurological reactions. These are widely used antimicrobials, which can cause cutaneous ADRs in about $1 \%-2 \%$ of patients. Hypersensitivity reactions due to ofloxacin are found rarely, ranging in frequency from $0.4 \%$ to $2 \%$, respectively. This case report highlights one such event of cutaneous ADR by the use of ofloxacin injection causing Injection site reaction after a few minutes of Ofloxacin infusion. Based on history and clinical examination patient was diagnosed as ofloxacin induced hypersensitivity reaction and was successfully treated with antihistamines and corticosteroids. General management of ADR includes withdrawal/suspension, dose reduction of the suspected drug, and administration of supportive therapy. In this case, the suspected drugs were withdrawn and the patient was treated symptomatically. Pharmacovigilance should be a part of patient care to reduce the occurrence of adverse drug reactions and also encourage practitioners in reporting to gather more and more data regarding adverse drug reactions.
\end{abstract}

Due to the rarity of Ofloxacin induced ADRs this article sheds light on one of such cases to help in pharmacovigilance

Keywords: Hypersensitivity reaction [HSR], Ofloxacin, Injection site reaction, Adverse drug reaction [ADR]

(C) 2022 The Authors. Published by Innovare Academic Sciences Pvt Ltd. This is an open access article under the CC BY license (https://creativecommons.org/licenses/by/4.0/) DOI: https://dx.doi.org/10.22159/ijpps.2022v14i3.43640. Journal homepage: https://innovareacademics.in/journals/index.php/ijpps.

\section{INTRODUCTION}

Ofloxacin is the most commonly used second-generation fluoroquinolone. It is generally used to combat various infections like Urinary Tracts Infection, Ocular, GE, etc. It acts by inhibiting bacterial DNA synthesis by inhibiting bacterial topoisomerase II [DNA Gyrase] and Topoisomerase IV. In vitro, it has a broad spectrum of activity against aerobic Gram-negative and Gram-positive bacteria. Although it is inadequate against anaerobes. Ofloxacin, unlike most other broadspectrum antibacterial drugs, can be administered orally as well as intravenously [1]. Ofloxacin is the $2^{\text {nd }}$ generation racemic mixture of $50 \%$ levofloxacin [L-isomer of the racemate ofloxacin, a quinolone antimicrobial agent]. and 50\% Detrofloxacin [2-4].

In clinical settings, ofloxacin is hugely used and is considered a safe drug, severe hypersensitivity reaction can occur with ofloxacin [3]. Hence this case report. Of all the organs affected by the adverse drug reaction [ADR], the skin is most frequently involved. Severe Cutaneous adverse reactions [SCAR] to drugs are observed in $0.1-1 \%$ of patients during pre-marketing clinical trials, and post-marketing analyses suggest that this incidence can be as high as 1-8\% for certain types of drugs [antibiotics, anti-epileptics] [4]. Antibiotic-induced hypersensitivity reaction can be of the following urticarial, angioedema, cutaneous reaction, anaphylaxis, and delayed response [5]. In antibiotics, beta-lactamase is the most common, quinolones, macrolide, sulphonamides, and infrequently fluoroquinolones.

Fluoroquinolones [FQs] are generally considered well-tolerated antibiotics and have been used for over $30 \mathrm{y}$ to treat a wide range of infections. IgE-mediated FQ ADR reporting has been increased over time. Both immediate and delayed reactions are seen in FQ. Immediate allergic reactions to $\mathrm{FQs}$ are difficult to diagnose, and the value of skin testing is controversial. Although few consider the test to be useful, the majority of the studies show that FQs induce falsepositive results; a possible explanation for this might be that some of FQs can directly induce histamine release [6]. And available tests are not risk-free. Different clinical categories are established: anaphylaxis and anaphylactic shock, defined according to the criteria of Sampson urticaria when manifested, are limited to the skin and consist of pruritic, erythematous cutaneous elevations with pressure at various sites on the body. Few causes of ADRs induced by FQs are their capacity to induce direct histamine release, mast cell receptor, Mas-related G-protein coupled receptor member X2[MRGPRX2] activation, which leads to rare instances of hypersensitivity/ anaphylactic reactions and other ADR which include gastrointestinal tract [nausea, vomiting, and diarrhea] in $<7 \%$ of cases and Central Nervous System [CNS] in $<5 \%$ cases [headache, dizziness, seizures] and uncommon adverse effects include renal disturbances [crystalluria, interstitial nephritis, acute renal failure], cutaneous hypersensitivity [Steven Johnson Syndrome, erythema, angioedema], photosensitivity, electrocardiogram abnormalities [QT interval prolongation], tendinitis and tendon rupture, impaired glucose metabolism and hepatic toxicity [7]. The hypersensitivity reactions to quinolones are rare with an incidence of $0.4 \%$ to $2 \%$ [8-10].

FQs are utilized in hemorrhoids which is a quite common anorectal disease defined as the symptomatic enlargement and/or distal displacement of anal cushions, which are prominences of anal mucosa formed by loose connective tissue smooth muscle, arterial and venous vessels. An ideal operation for hemorrhoids should remove the internal and external components of hemorrhoids completely, have minimal postoperative pain and complication, demonstrate less recurrence, and be easy to learn and perform. The procedure could be cheap and cost-effective, too but none of the above operations can achieve all conditions. Haemorrhoidectomy is the mainstay operation for grade IIIV hemorrhoids and complicated hemorrhoids [11].

Here we report a case of ADR caused due to ofloxacin at injection site reaction. Ofloxacin ADR literature has a paucity and hence we are reporting it intending to make clinicians vigilant about this rare association.

\section{CASE REPORT}

A 39-year-old male patient presented with complaints of severe pain while passing stools for one week. He was diagnosed with Chronic fissure in Ano and Grade-II Internal Haemorrhoids. He underwent lateral sphincterotomy+Hemorrhoidectomy. The patient is Allergic 
to Inj. Diclofenac. Laboratory tests for complete blood pictures were under normal limits.

The patient was prescribed with Inj. Ofloxacin after surgery. After a few minutes of infusion of ofloxacin, he developed severe Hypersensitivity reaction to ofloxacin such as pain, rash, and redness at the site of injection. The drug infusion was stopped immediately, vitals were checked. On examination patient was conscious, oriented, and stable with BP: 110/70, Afebrile, $\mathrm{SPO}_{2}-98$. Laboratory findings did not reveal any significant abnormality. Considering the clinical examination patient was diagnosed as a case of Hypersensitivity reaction to Ofloxacin. The patient was managed with Inj. Avil $1 \mathrm{Amp}$ Stat, Inj. Hydrocort Stat and Normal saline infusion. Symptoms of reaction subsided after ofloxacin was stopped and the patient was kept under observation for $24 \mathrm{~h}$.

Further, Re-challenge with the same drug was not done; instead drug was replaced with Inj. Taxim 1 gm IV BD, Inj. Metrogyl $500 \mathrm{mg}$
IV TID and Inj. Tramadol $100 \mathrm{mg}$ IV for pain [Diclofenac was avoided since the patient is Allergic to Inj. Diclofenac]. When symptoms improved patient was discharged in stable condition. The adverse drug reaction assessment was done using Naranjo's causality assessment scale, which showed the 'Probable' type of adverse drug reaction with ofloxacin. The clinical features with which he presented were similar to those seen in a typical case of fixed druginduced hypersensitivity reaction. A skin prick test [SPT] was performed with ofloxacin at a concentration of $10 \mathrm{mg} / \mathrm{ml}$ using distilled water. $1 \mathrm{mg} / \mathrm{ml}$ histamine and normal saline were used as negative and positive controls, respectively. SPT was regarded as positive when a wheal larger than $3 \mathrm{~mm}$ with surrounding erythema was seen $15 \mathrm{~min}$ after exposure.

The being illiterate was not able to sign a written consent and so verbal consent was taken along with his family members after explaining that his case shall be turned to a case report form of article and will help in pharmacovigilance.

Table 1: Laboratory data on day of occurance of the adr

\begin{tabular}{|c|c|c|c|c|}
\hline S. No. & Lab parameters & & Observed values & Normal range \\
\hline 1. & Haemoglobin & & $14.3 \mathrm{~g} / \mathrm{dl}$ & $13-15 \mathrm{~g} / \mathrm{dl}$ \\
\hline 2. & Packed Cell Volume & & $40 \%$ & $40-50 \%$ \\
\hline 3. & RBC Count & & 4.9 million cells $/ \mathrm{mm}^{3}$ & 4.5-6.5 million $/ \mathrm{mm}^{3}$ \\
\hline 4. & Total Leukocyte Count & & 10,800 cells $/ \mathrm{mm}^{3}$ & $4,000-11,000$ cells $/ \mathrm{mm}^{3}$ \\
\hline \multirow[t]{5}{*}{5.} & Differential Leukocyte & Neutrophils & $57 \%$ & $40-75 \%$ \\
\hline & Count & Eosinophils & $2 \%$ & $2-6 \%$ \\
\hline & & Basophils & 0 & $0-1 \%$ \\
\hline & & Lymphocyte & $38 \%$ & $20-45 \%$ \\
\hline & & Monocytes & $4 \%$ & $2-8 \%$ \\
\hline 6. & Platelet count & & 2.8 lakh cell $/ \mathrm{mm}^{3}$ & 1.5-4.5 lakh $/ \mathrm{mm}^{3}$ \\
\hline
\end{tabular}

\section{DISCUSSION}

Anaphylactic HSR could be acute onset and unpredictable due to the sudden release of mediators like histamine from mast cells and basophils. Symptoms include generalized macula papulae, wheals, erythema, pruritus and angioedema, drug-induced maculopapular exanthema [DIMPE]. DIMPE consists of diffuse cutaneous erythema with areas of skin elevation, sometimes accompanied by angioedema that in some instances may evolve to vesicles.

The pathogenesis of anaphylaxis caused by ofloxacin is not yet fully understood, as it is not commonly reported. The most common adverse events associated with quinolones are usually mild and do not require hospitalization [12].

The true prevalence of quinolone allergy in the general population is unknown. Quinolone allergy can be largely classified into two types: Ig-E mediated immediate reactions [IRs], which occur less than one hour after administration which has happened in this case and the other type is T-cell mediated delayed reactions [DRs], which occur more than an hour after administration and IR is mostly seen [70\%]. Diagnostic tests include skin tests, drug provocation tests [DPT], and in vitro laboratory tests. However, skin tests and in vitro tests have displayed low sensitivity and specificity therefore their diagnostic dependability is questionable. Invitro tests for quinolone allergy are not available. IgE-mediated pathological characteristic is mast-cell degranulation. Examples of IgE-mediated responses include urticaria, anaphylaxis, asthma, rhinitis, and angioedema. Quinolone allergy management is based on three foundational principles: discontinuation of the offending agent, initiation of an alternative agent, and supportive care such as corticosteroid therapy, fluid replacement with electrolytes, and albumin substitution. There is conflicting evidence regarding cross-reactivity among the quinolone drug class [5].

Immediate type of HSR is rare with FQ; only about $2 \%$ of patients experience such reaction. No previous studies confirm or rule out cross-reactivity with other quinolones. Studies state that the level of cross-reactivity between quinolones is high and if a patient is allergic to one agent of the group, then all quinolones should be avoided. There is no way of predicting cross-reactivity. Different patterns of cross-reactivity could be present in immediate-type reactions. Cross-reactivity is related to quinolone ring and it is found that neither skin testing nor flow cytometric Basophil Activation Test helped predict cross-reactivity to quinolones or in establishing a diagnosis. It is necessary to confirm low cross-reactivity to other quinolones, such as ofloxacin, which was not performed here $[5,12]$.

There are cases of IgG4-mediated but not IgE-mediated mechanism in a patient with ofloxacin-induced anaphylaxis. If serum-specific IgE antibody was not detected in the patient's serum, while high serumspecific IgG4 antibody was detected. BAT can be used to detect such HSR [13].

Few studies have investigated the role of specific IgG in antibiotic allergies. In those studies, subjects had high specific IgG4 levels, which suggest a parallel immune response with specific IgE, but without a pathologic role conclusion, we suggest that an IgEmediated response to the hapten part of ofloxacin is the major pathogenic mechanism underlying ofloxacin hypersensitivity [13].

IgEs cross-react with both quinolones. There are acuminous that immediate allergic hypersensitivity to quinolones is associated with NMBA sensitization, although its clinical relevance remains undefined. Patients with quinolone immediate allergic hypersensitivity display a significantly higher prevalence of QA sensitization than patients with quinolone immediate nonallergic hypersensitivity reactions and the general population. The key pathogenic mechanism behind ofloxacin hypersensitivity is an IgEmediated response to the hapten component of the drug [14, 15].

Fluoroquinolones induced fixed drugs eruption pathogenesis is not known; antibodies, cell-mediated cytotoxicity, and other serum factor roles have been implicated. Few hypotheses are involvement of type IVc immunological reaction because of latent cytotoxic T cells in the lesion, which gets reactivated, another reason may be involvement of class I antigen or maybe the result of mechanism, based on mast cells [MCs] activation utilizing the G-protein coupled receptor x2 [mrgprx2].

Systemic mast cell degranulation is responsible for the hypersensitive reaction; in many instances IgE-mediated [12] 
Mastocyte-related G-protein coupled receptor X2 [MRGPRX2], Masrelated gene [Mrg] receptor Mrgprb2. was able to demonstrate that this receptor upon activation with some drugs, is capable of producing direct $\mathrm{MC}$ degranulation and anaphylactic reactions. MRGPRX2 was found to be expressed in sensory neurons, mast cells, and, most recently, in keratinocytes [14, 16-19]. MRGPRX2 mRNA is present in adipose tissue, esophagus, urinary bladder, lungs, with the highest levels found in the skin. Skin seems to be an important organ associated with MRGPRX2-dependent reactions [14, 17-20].

Four fluoroquinolones approved for use IV use [ciprofloxacin, moxifloxacin, levofloxacin, ofloxacin] may activate MCs through MRGPRX2 and Mrgprb2 [14, 19].

The adverse drug reaction assessment was done using "Naranjo's causality assessment scale" which showed a 'probable' type of reaction involving ofloxacin.

ADRs found after post-market surveillance in Japan of ofloxacin were gastrointestinal distress, such as pain, nausea, diarrhea, skin rash, angioedema, pruritis, CNS epilepsy, and their occurrences in the above order. Sex did not affect the rate of incidence and older patients [less than60] were affected more. Eruptions and itching were the most common HSR, of which most were spontaneous.

ADR symptoms of ofloxacin observed after post surveillance in Germany were mostly mild and mainly related to the gastrointestinal tract. The next most common adverse drug events were nervous symptoms and hypersensitivity reactions; the most frequent central nervous system symptoms [headache, insomnia, restlessness, and dizziness] generally occurred on the first day of therapy and subsided quickly after discontinuation of ofloxacin. Sometimes, these symptoms disappeared without treatment. Hypersensitivity Rash and other mild hypersensitivity reactions were reported in clinical trials. Other Adverse Drug Events Increases in serum concentrations of y-glutamyl transpeptidase, aspartate aminotransferase, alanine aminotransferase or creatinine, or a reduction in creatinine clearance were observed very infrequently [10].

\section{CONCLUSION}

Although $\mathrm{FQs}$ are considered safe and fewer side effects are reported, proper history should be taken before prescribing ofloxacin here; we show a case of HSR caused due to ofloxacin is reported inpatient who experienced allergic reaction due to diclofenac along with HSR to ofloxacin. This case study is intended to show such ADRs and promote reports of such cases to improve the knowledge of practitioners and improve pharmacovigilance.

\section{LIST OF ABBREVIATIONS}

ADR: Adverse Drug Reaction, CNS: Central Nervous System, FQ: Fluoroquinolones, HSR: Hypersensitivity Reaction, Inj: Injection, IRs: Ig-E mediated immediate reactions, MRGPRX2: Mas-related G-protein coupled receptor member X2, Mrg: Mas-related gene, MC: Mast cells

\section{ACKNOWLEDGMENT}

Not applicable

\section{FUNDING}

Nil

\section{AUTHORS CONTRIBUTIONS}

BD analyzed the patient and identified the adverse drug event and provided the required literature. LT further provided evidence through literature review and contributed to the major part of the manuscript. All authors read and approved the final manuscript.

\section{CONFLICT OF INTERESTS}

Declared none

\section{REFERENCES}

1. Todd PA, Faulds D. Ofloxacin a reappraisal of its antimicrobial activity, pharmacology and therapeutic use. Drugs. 1991 Nov;42(5):825-76. doi: 10.2165/00003495-199142050-00008, PMID 1723377.
2. Method development and validation of simultaneous determination of ofloxacin and satranidazole in pharmaceutical dosage form by RP-HPLC | Abstract [internet]. Vol. 9480. Available from: https://www.scholarsresearchlibrary.com/ abstract/method-development-and-validation-ofsimultaneous-determination-of-ofloxacin-and-satranidazolein-pharmaceutical-dosage.html. [Last accessed on 13 Oct 2021]

3. Kumar A, Tiwari BK, Kumar S. Evaluation of ocular films of ofloxacin for antibacterial activity. Int J App Pharm. 2018 Nov 7;10(6):275-89. doi: 10.22159/ijap.2018v10i6.27188.

4. Shahwal V, Kumar DBK, Bhoumick M. Preformulation study of levofloxacin. Int J Adv Pharm. 2012;1(1):1-8.

5. Neki NS. Hypersensitivity reaction to ofloxacin: a case report. J Chitwan Med Coll. 2015;5(4):75-7. doi: 10.3126/jcmc.v5i4.16558.

6. Hosaka H, Ohtoshi S, Nakada T, Iijima M. Erythema multiforme, Stevens-Johnson syndrome and toxic epidermal necrolysis: frozen-section diagnosis. J Dermatol. 2010 May;37(5):407-12. doi: 10.1111/j.1346-8138.2009.00746.x, PMID 20536645.

7. Worm M, Hanschmann Mohn T, Scherer Hofmeier K, Cardona V, Turner P, Dolle-Bierke S. Drug-induced anaphylaxis-elicitors, mechanisms and diagnosis. Allergo J Int. 2019 Dec 1;28(8):3279. doi: 10.1007/s40629-019-00109-2.

8. Ofloxacin Induced Hypersensitivity Reaction | Chetna DesaiAcademia. Available from: https://www.academia.edu/ 50356051/Ofloxacin_Induced_Hypersensitivity_Reaction. [Last accessed on 13 Oct 2021].

9. Azimi E, Reddy VB, Lerner EA. Brief communication: MRGPRX2, atopic dermatitis and red man syndrome. Itch Phila Pa. 2017 Mar;2(1):e5.

10. Sawada M, Nakamura S, Yamada A, Kobayashi T, Okada S. Phase IV study and post-marketing surveillance of ofloxacin in Japan. Chemotherapy. 1991;37(2):134-42. doi: 10.1159/000238845, PMID 2032469

11. Blanca Lopez N, Andreu I, Torres Jaen MJ. Hypersensitivity reactions to quinolones. Curr Opin Allergy Clin Immunol. 2011 Aug;11(4):285-91. doi: 10.1097/ACI.0b013e3283489bc3, PMID 21659860.

12. Jungst G, Mohr R. Side effects of ofloxacin in clinical trials and in postmarketing surveillance. Drugs. 1987 Oct 1;34(1) Suppl 1:1449. doi: 10.2165/00003495-198700341-00031, PMID 3325257.

13. Lohsiriwat V. Treatment of hemorrhoids: A coloproctologist's view. World J Gastroenterol. 2015 Aug 21;21(31):9245-52. doi: 10.3748/wjg.v21.i31.9245, PMID 26309351.

14. McNeil BD, Pundir P, Meeker S, Han L, Undem BJ, Kulka M, Dong X. Identification of a mast-cell-specific receptor crucial for pseudoallergic drug reactions. Nature. 2015 Mar 12;519(7542):237-41. doi: 10.1038/nature14022, PMID 25517090.

15. Kim JH, Seo DH, Ban GY, Yang EM, Shin YS, Ye YM, Park HS. An ofloxacin-induced anaphylaxis through an IgG4-mediated but not IgE-mediated basophil activation mechanism. Korean J Crit Care Med. 2017 Aug 1;32(3):302-5. doi: 10.4266/kjccm.2017.00108, PMID 31723651.

16. Porebski G, Kwiecien K, Pawica M, Kwitniewski M. Mas-related $\mathrm{g}$ protein-coupled receptor-X2 (MRGPRX2) in drug hypersensitivity reactions. Front Immunol. 2018;9:3027. doi: 10.3389/fimmu.2018.03027, PMID 30619367.

17. Aranda A, Mayorga C, Ariza A, Doña I, Rosado A, Blanca Lopez N, Andreu I, Torres MJ. In vitro evaluation of IgE-mediated hypersensitivity reactions to quinolones. Allergy. 2011 Feb;66(2):247-54. doi: 10.1111/j.1398-9995.2010.02460.x, PMID 20722637.

18. Lembo PMC, Grazzini E, Groblewski T, O’Donnell D, Roy MO, Zhang J, Hoffert C, Cao J, Schmidt R, Pelletier M, Labarre M, Gosselin M, Fortin Y, Banville D, Shen SH, Ström P, Payza K, Dray A, Walker P, Ahmad S. Proenkephalin A gene products activate a new family of sensory neuron-specific GPCRs. Nat Neurosci. 2002 Mar;5(3):201-9. doi: 10.1038/nn815, PMID 11850634.

19. Liu R, Hu S, Zhang Y, Che D, Cao J, Wang J, Zhao T, Jia Q, Wang N, Zhang T. Mast cell-mediated hypersensitivity to fluoroquinolone is MRGPRX2 dependent. Int Immunopharmacol. 2019 May 1;70:417-27. doi: 10.1016/j.intimp.2019.02.001, PMID 30856392. 
20. Dong X, Han S, Zylka MJ, Simon MI, Anderson DJ. A diverse family of GPCRs expressed in specific subsets of nociceptive sensory neurons. Cell. 2001 Sep 7;106(5):619-32. doi: 10.1016/s0092-8674(01)00483-4, PMID 11551509.
21. Roy S, Ganguly A, Haque M, Ali H. Angiogenic host defense peptide $\mathrm{AG}-30 / 5 \mathrm{C}$ and Bradykinin $\mathrm{B} 2$ receptor antagonist Icatibant are $\mathrm{G}$ protein-biased agonists for MRGPRX2 in mast cells. J Immunol Baltim Md 1950. 2019 Feb 15;202(4):1229-38. 